\title{
Bell's palsy together with scarlet fever in a child: A rare case
}

\author{
Veysel Kars ${ }^{1}$, Ahmet Yilmaz ${ }^{1}$, Tahsin Celepkolu ${ }^{1}$, Hamza Aslanhan ${ }^{1}$, Necmi Arslan ${ }^{1}$, Vasfiye \\ Demir $^{1}$, Abdullah Cim ${ }^{2}$
}

Abstract

Scarlet fever is an infectious disease caused by the erythrogenic toxin produced by $\beta$-hemolytic streptococci. The prodrome phase is 12-24 hours with fever, emesis, sore throat, and headache. If not treated, the fever rises up to $39.5{ }^{\circ} \mathrm{C}$ and may last up to 5-7 days. Complications may occur in case of a prolonged prodrome. We report a five-year-old child who presented with Bell's paralysis together with scarlet fever. We emphasize that facial paralysis should be take into consideration in the treatment and follow-up of the patients presenting with scarlet fever

Key words: Scarlet fever, Bell's palsy, Petechiae

\section{Introduction}

Scarlet fever (SF), caused by the erythrogenic toxin produced by Group A $\beta$ hemolytic streptococci, is an infectious disease characterized by widespread erythematous rash. Once the patient has been exposed to this toxin, protective antibodies are developed and the toxin is neutralized. Therefore, erythematous rash is seen when no protective antibodies are present. SF has an average incubation period of 1-7 days. The prodrome phase of SF is 12-24 hours of fever, emesis, sore throat, and headache. If not treated, the fever rises up to $39.5^{\circ} \mathrm{C}$ and may last up to 5-7 days. The use of penicillin can bring down the fever in 12-24 h. SF leads to erythematous rash which includes enanthema and exanthema. It may also represent with tonsillar exudate or palatal petechia. At first two days white strawberry tongue is represent because of hyperceratotic membrane. On the $4^{\text {th }}$ and $5^{\text {th }}$ day membrane sheds to reveal a bright red mucosa and red strawberry tongue shows up. On the proximal part of body, scarlanitiform shaped punctiform papules that resemble sandpaper occur whereon erythroderma and then these papules spread to the whole body in 4-5 days. These papules, particularly the ones on the hands and feet, are resolved via desquamation. Also, Pastia's lines become visible, which are brighter red than the rest of the rash.

The anatomy and function of the facial nerve (FN) was first described by Sir Charles Bell in early 1800 s. The facial nerve is a complex nerve which includes the motor fibers innervating the facial muscles; the parasympathetic fibers innervating lacrimal, submandibular, and sublingual salivary glands; the afferent fibers from taste receptors from the anterior two thirds of the tongue; and the somatic afferents from the external auditory canal and pinna. Bell's paralysis (BP) is mostly seen among 15-45 year old patients, and the incidence rate is $10-40 / 100.000$ with no obvious sexual predominance. Upper respiratory tract infections such as influenza and common cold, tooth extraction, and long-term exposure to cold air and wind are reported as the history of BP $[1,2]$. Moreover, two-thirds of facial nerve paralysis (FNP) cases are diagnosed as idiopathic since they represent no clear etiology [3]. Clinical presentation of FNP is characterized by unilateral facial paralysis, impaired platysma muscle, drooping of the corner of the mouth and the forehead, and difficulty in closing the eye or the mouth [4]. BP is generally diagnosed via patient's history and the findings of physical examination, without any need for diagnostic imaging and routine laboratory testing [7]. BP is the most common cause of unilateral facial paralysis and constitutes $60-75 \%$ of all cases of FNP $[5,6]$. Although the incidence of $\mathrm{BP}$ in children remains unknown, Peitersen reviewed 2,500 BP cases and reported the incidence for children below 15 years of age as $14 \%$ [6]. BP has a better prognosis for the patients below 20 years of age; however, the rate of complete recovery decreases by age [7]. There are several theories for the cause of peripheral facial nerve paralysis (PFP); some studies argue that PFP results from the local ischemia in the nerve cause by the

Received 12-12-2014, Accepted 01-08-2015, Available Online 22-01-2015

${ }^{1}$ Dicle University, Faculty of Medicine Dept. of Family Medicine, Diyarbakir, Turkey

${ }^{2}$ Dicle University, Faculty of Medicine Dept. of Medical Genetic, Diyarbakir, Turkey

*Corresponding Author: Veysel Kars E-mail: dr.haber@hotmail.com

This case report was presented as a poster presentation in the 25th Turkish National Congress of Dermatology, 21-25 October 2015, Rixos Sungate Hotel, Antalya 
vasoconstriction in the fallopian canal, whereas the others claim that PFP is a result of direct invasion of the nerve by the toxins that are produced by the infectious agents [8].

Facial nerve consists of intracranial, intra temporal, and extra temporal segments [9]. In central facial palsy, the function of the fibers innervating the forehead is normal due to the supra nuclear fibers that are connected with ipsi lateral cortex. However, nuclear and peripheral facial paralyses are often accompanied by loss of function fibers function in the affected side of the face [10]. Various facial grading systems have been developed by House-Breckmann, Sunnybrook, Burres-Fisch, MoReSS, Sydney, and Yanagihara. Of these, the one developed by Yana gihara is the most commonly used [11].

\section{Case}

A five-year-old girl presented to the family physician with fever, sore throat, and discomfort, and then she was orally administered amoxicillin, decongestant and antipyretic. On the following days, the parents failed to administer the drugs due to the child's continuous discomfort. On the $5^{\text {th }}$ day of treatment, the body temperature suddenly increased to $40{ }^{\circ} \mathrm{C}$ and thereafter the patient represented to our clinic with fever, abdominal pain, rash in groins and darkening of urine. During the physical examination, the tonsils were hyperaemic and hypertrophic; the tongue had a strawberry appearance. $5 \times 5 \mathrm{~cm}$ squamous lesion was detected on the left armpit and a bright red macula papullar rash had been spread whole body predominantly to the groins. The ear examination was uneventful, except for mild hyperaemia in the outer ear canal. The patient was extremely sensitive to the slightest noise. When she cried, the left side of her mouth drooped and her right eye remained open. The sclera was slightly pale, but no jaundice was detected in any part of the body. Temperature was $39.6{ }^{\circ} \mathrm{C}$, ALT and AST levels were normal, leukocyte count was $8.900 / \mathrm{mm} 3$, and thrombocyte count was 180.000 . The patient had no family history of BP, and her weight and height were in the $50^{\text {th }}$ percentile (Figure 1). Streptococcus pyogenes reproduced in patient's throat cultures. The patient who has had both scarlet fever and FNP was administered a course of steroid and antibiotic therapy. Clinical improvement was seen within the first week and the facial paralysis completely resolved on day $14^{\text {th }}$

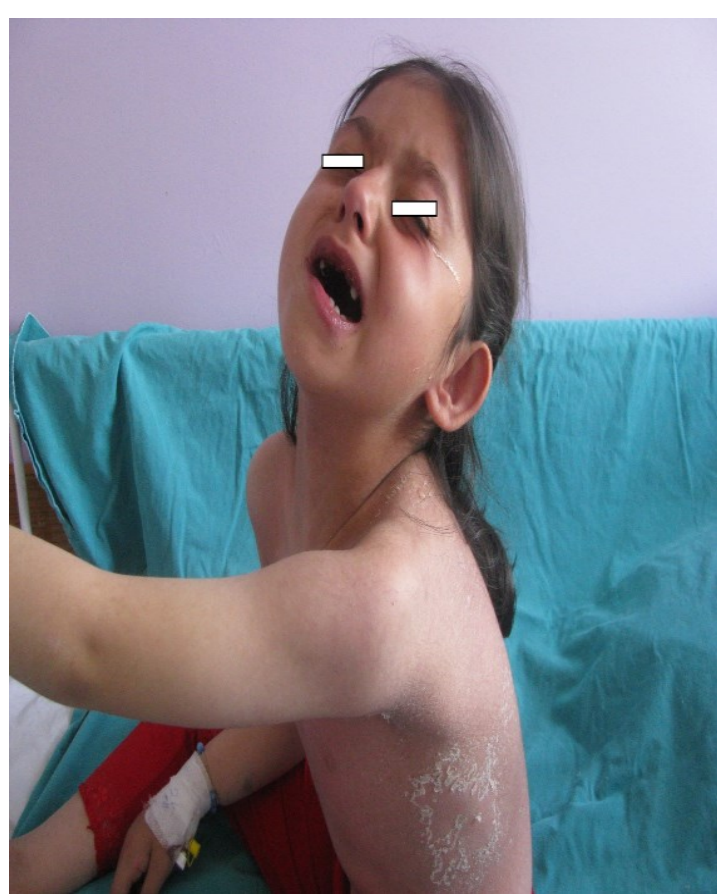

Figure 1: Distinctive desquamative lesions and facial palsy in the patient

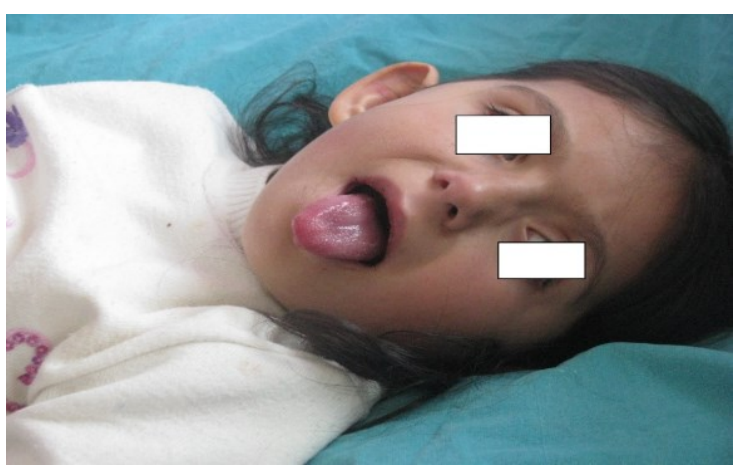

Figure 2: Marked improvement of the patient on the $14^{\text {th }}$ day of treatment

\section{Discussion}

Facial nerve paralysis may resolve within one year. While spontaneous or complete recovery can be seen in $80-85 \%$ of the patients, mild nerve damage can be seen in $15-20 \%$ and severe nerve damage can be seen in $5 \%$ of the patients $[3,12]$. The infections caused by Group A $\beta$-hemolytic streptococci (GABHS) may be accompanied by otitis, sinusitis, meningitis, hepatitis, and scarlet fever [13]. Prompt treatment of scarlet fever decreases the infection and facilitates the recovery process. The ideal treatment includes amoxicillin for 10 days or intramuscular penicillin administration. With prompt treatment, the symptoms can resolve quicker and also the neurological complications can be prevented. Our patients presented to us with PFP on the $5^{\text {th }}$ day after the onset of fever. The patient was administered parenteral ampicillin and antipyretic. The patient clinically improved within the first 
week, and the facial paralysis completely resolved on day 14 (Figure 2).

Conflict of Interest: The authors declare no potential conflicts of interest with respect to the research, authorship, and/or publication of this article.

\section{References}

1. Zaidi FH, Gregory-Evans K, Acheson JF, Ferguson V. Familial Bell's palsy in females: a phenotype with a predilection for eyelids and lacrimal gland. Orbit.; 2005, 24:121-24.

2. Morris AM, Deeks SL, Hill MD, Midroni G, Goldstein WC, Mazzulli T, Davidson R, Squires SG, Marrie T, McGeer A, Low DE . Annualized incidence and spectrum of illness from an outbreak investigation of Bell's palsy. Neuro epidemiology.; 2002, 21:255-61.

3. Peitersen E. Bell's palsy: the spontaneous course of 2,500 peripheral facial nerve palsies of different etiologies. Acta Otolaryngol Suppl; 2002, 549:4-30.

4. Holland NJ, Weiner GM. Recent developments in Bell's palsy. Br Med J.; 2004, 329:553-7.

5. Rahman I, Sadiq SA. Ophthalmic management of facial nerve palsy: a review. Surv Ophthalmol; 2007, 52: 12144.

6. Kaygusuz I, Gödekmerdan A, Keleş E, Karlidağ T, Yalçin S, Yildiz M, Tazegül A. The role of viruses in idiopathic peripheral facial palsy and cellular immune response. Am J Otolaryngol; 2004, 25: 401-6.

7. Kasse CA, Cruz OL, Leonhardt FD, Testa JR, Ferri RG, Viertler EY. The value of prognostic clinical data in Bell's palsy. Braz J Otorhinolaryngol; 2005, 71: 454

8. Joseph EM, Sperling NM. Facial nerve paralysis in acute otitis media: cause and management revisited. Otolaryngol Head Neck Surg; 1998, 118:694-6. PMid:9591875

9. Philips CD, Bubash LA. The facial nerve: anatomy uncommon pathology. Semin Ultrasound CT MR; Jun 2002, 23:202-17.

10. Adour KK. Hilsinger RL Jr and Callan EJ (1985). Facial paralysis and Bell's palsy: A protocol for differential diagnosis. Am J Otol (Suppl), Nov.

11. Kanerva M, Poussa T, Pitkäranta A. Sunnybrook and House-Brackmann Facial Grading Systems: intrarater repeatability and interrater agreement. Otolaryngol Head Neck Surg.; 2006, 135:865-71.

12. Tiemstra JD, Khatkhate N. Bell's palsy: diagnosis and management. Am Fam Physician; 2007, 76:997-1002.

13. Bisno AL, Stevens DL. Streptococcus pyogenes (Including streptococcal toxic shock syndrome and necrotizing fasciitis).Principles and practice of infectious diseases. Churchill Livingstone, Inc., New York, N.Y. 2000, 6:2101-116. 